\title{
AUTONOMIC CORRELATES OF THE SUBJECTIVE ANXIETY SCALE*
}

\author{
BRUCE A. THYER, + JAMES D. PAPSDORF, RANDALL DAVIS and \\ SUSAN VALLECORSA
}

The University of Michigan, Ann Arbor

\begin{abstract}
Summary-The subjective anxiety scale is an assessment tool commonly used in behavioral research and therapy to quantify verbal report of private events, usually states of fear. An investigation was undertaken to determine the extent of relationship between the subjective anxiety scale and two concurrent measures of autonomic arousal, peripheral vasoconstriction and heart rate. Measures were recorded during baseline, surgical film and second baseline phases for 20 subjects. The subjective and autonomic measures indicated increased anxiety during the film phase and significant correlations were found between subjective report of anxiety and the two physiological indices. The results support the continued use of the subjective anxiety scale as a clinical assessment tool. Practice and research implications are discussed.
\end{abstract}

Behavioral researchers have repeatedly advocated the use of multiple response system assessment of psychological phenomena (Lang, 1968). In this approach the dependent variables are measured by means of the subject's or client's self-report, systematic recording of overt behavior and the assessment of relevant physiological variables. In an ideal situation, these three response channels produce synchronous results. For example, in the measurement of phobic anxiety, the client reports acute fear and at the same time has an elevated heart rate and attempts to avoid the anxiety evoking stimulus. Uniform elevations in all three response channels provides unambiguous evidence for the existence of "phobic anxiety". Instances of overt avoidance without fear, or behavioral approach while heart rate remains high, are examples of the phenomenon of desynchrony between response channels (Rachman and Hodgson, 1974; Hodgson and Rachman, 1974; Grey, Sartory and Rachman, 1979), and allow less clear cut interpretation of results.
The matter of synchrony or desynchrony between response channels is not only of interest to the behavioral researcher but is important to the clinician as well. It is known that during exposure therapy for phobic disorders, for example, a cognitive lag effect often occurs, with most subjects improving first on measures of overt avoidance behavior while remaining acutely anxious as measured by selfreport (Watson, Gaind and Marks, 1972). It has been suggested that more enduring therapeutic effects are likcly to rcsult if treatment is continued past the period of desynchrony, until all three response channels indicate congruent improvements (Thyer, 1981).

In the clinical setting the response channel most frequently relied upon is the self-report of the client. Information can be obtained via selfreport through a variety of methods such as structured or unstructured interviews, psychological tests, questionnaires, fear survey schedules, inventories and so fcrth. Recent reviews of the role self-report information plays in behavioral assessment can be found in

*Portions of this paper were presented at the meeting of the Association for Advancement of Behavior Therapy, Toronto, 12-15 November 1981.

†Requests for reprints should be sent to Bruce A. Thyer, Anxiety Disorders Program, Department of Psychiatry, The University of Michigan Hospitals, Ann Arbor, Michigan 48109, U.S.A. 
Meyer, Liddell and Lyons (1977), Tasto (1977) and Ciminero, Nelson and Lipinski (1977). It has been frequently stated that the relationship between self-report measures of events and the corresponding behavioral and physiological indices is generally quite low (Mishel, 1968; Leitenberg et al., 1971), although this varies according to the specific measures employed. Psychometric theory addresses this issue with respect to standardized tests and measures (Nunally, 1978).

What is probably the most frequently employed structured self-report measure in behavior therapy is the use of a subjective anxiety scale. Most commonly used in the assessment and treatment of anxiety related disorders, the use of the subjective anxiety scale (SUD* scale) was introduced by Wolpe (1969) as a method for the clinician to use in estimating the magnitude of the client's response to fear provoking cues. As Wolpe described, "The scale is introduced to the client by addressing him as follows: 'Think of the worst anxiety you have ever experienced, or can imagine experiencing, and assign to this the number 100. Now think of the state of being absolutely calm and call this zero. Now you have a scale of anxiety. On this scale how do you rate yoursclf at this moment?' Most subjects give a figure without much hesitation, and with practice come to be able to indicate their feelings with increasing confidence in a way that is much more informative than the usual adjectival statements" (Wolpe, 1973, p. 120).

Commonly used in the conduct of systematic desensitization in fantasy and real life exposure therapy for phobias, the subjective anxiety scale has been modified for use in the assessment of sexual arousal in men (Farkas, Sine and Evans, 1979) and women (Wincze, Hoon and Hoon, 1977), obsessive-compulsive urges (Foa and Chambless, 1978) and the desire to drink alcohol (Hodgson and Rankin, 1976; Blakey and Baker, 1980). Subjective estimates of sexual arousal have been found, in a number of subjects, to be significantly correlated with measures of penile tumesence (Farkas, Sine and Evans, 1979) and vaginal vasocongestion (Wincze, Hoon and Hoon, 1977), providing validation data supportive of the use of such self-report scales in the assessment and treatment of sexual dysfunction. A review of the literature on the use of the subjective anxiety scale revealed that few investigations have been conducted on the validity of such estimates. The present exploratory investigation was undertaken to determine the relationship existing between subject's self-report of anxiety and two physiological indices of autonomic arousal, heart rate and peripheral vasoconstriction.

\section{Subjects \\ METHOD}

Subjects were 20 volunteer undergraduate students, 10 males and 10 females, who had a mean age of $20 \mathrm{yr}$. Prior to the experiment, subjects completed the Trait Anxiety Inventory (Spielberger, Gorsuch and Lushene, 1970) and the Wolpe-Lang (1977) Fear Survey Schedule. Mean scores for these inventories were 65 and 38 points respectively, essentially within normal limits for undergraduates.

\section{Measures}

Two different indices of autonomic arousal were employed. Peripheral vasoconstriction, reflected by changes in digit temperature, was monitored as this measure is indicative of sympathetic arousal (Wolf, 1979) and has been shown to be responsive to stress induction procedures (Boudewyns, 1976; Crawford, Friesen and Tomlinson-Keasey, 1977). Heart rate was also measured as this response is sensitive to changes in autonomic arousal (Obrist, 1976) and levels of fear (Leitenberg et al., 1971; Watson, Gaind and Marks, 1972). The subjective variable was the self-report of anxiety as formulated in the subjective anxiety scale described by Wolpe (1973, p. 120).

\section{Apparatus}

Measures of digit temperature were recorded from thermistors taped to the distal phalange of the middle finger of each hand. Skin temperature was monitored by two Coulbourn Instruments Temperature Biofeedback Units driven by a Coulbourn Instruments Solid State Power Supply. Temperature readings were recorded from two Simpson Digital Multimeters, Model 460. Heart rate was monitored with a Gulf and Western cardiotach (series 4600) which displayed an average beat per minute for the last four seconds. The cardiotach photoplethysmograph was attached to the index finger of the subject's left hand. The independent variable consisted of a $3 \mathrm{~min}$ color videotape depicting a venous cutdown procedure. A surgically prepared arm was displayed which was multiply 
infiltrated by a syringe with anesthetic. Infiltration was followed by the venous cutdown. A previous study demonstrated the effectiveness of viewing this film as a stress induction procedure (Curtis and Thyer, 1983).

\section{Procedure}

Upon arriving at the laboratory, subjects were seated in a comfortable armchair which faced a color videotape playback unit. The physiological monitoring equipment and experimenter were located behind the subject, out of his line of vision. The thermistors and photoplethysmograph were attached and the subject given the following instructions:

In this study we are interested in changes in certain physiological responses people experience as a result of watching a mildly stressful film depicting a minor surgical procedure. Periodically throughout the experiment I will ask you to give me a rating of how anxious or upset you are. Think of the worst anxiety you have ever experienced or can imagine experiencing, and assign to this the number 100 . Now think of the state of being absolutely calm and call this zero. Now you have a scale of anxiety. On this scale, how do you rate yourself at this moment?

After it was clear that the subject understood the subjective anxiety scale, he was asked to relax and to look at the blank television screen. Measures were recorded for subjective anxiety, bilateral hand temperature and pulse every minute for a $10 \mathrm{~min}$ baseline period. At the end of the first baseline period the experimenter started the videotape and instructed the subject to continue to look at the television screen and to try to observe the entire videotape without looking away. Measures were recorded at $30 \mathrm{sec}$ intervals during the $3 \mathrm{~min}$ duration of the tape and at the conclusion of the film the subject was instructed to continue to look at the blank television screen. Measures were recorded at $1 \mathrm{~min}$ intervals during the second $10 \mathrm{~min}$ baseline. At the conclusion of the experiment, the sensors were removed, the subject debriefed, thanked and excused.

\section{RESULTS}

The data for all 20 subjccts was averaged for each sampling interval and these mean values are displayed in Fig. 1. Evidence that the film viewing procedure was effective at inducing strong autonomic arousal is found in that the film phase of the experiment is associated with a marked elevation in heart rate and decreases in peripheral hand temperature, reflective of vasoconstriction. These changes were observed to occur concurrently with elevations in the subjects' self-report of anxiety. The degree of synchrony existing between these averaged measures was analyzed using the Spearman Rank-order correlation statistic (Hays, 1963). The correlations are presented in Table 1. The self-report of anxiety, as measured by Wolpe's subjective anxiety scale, was found to correlate significantly in the predicted direction with both measures of autonomic arousal. Elevations
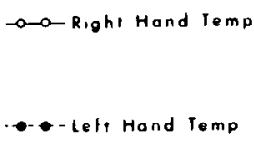

$\rightarrow-$ SUDS
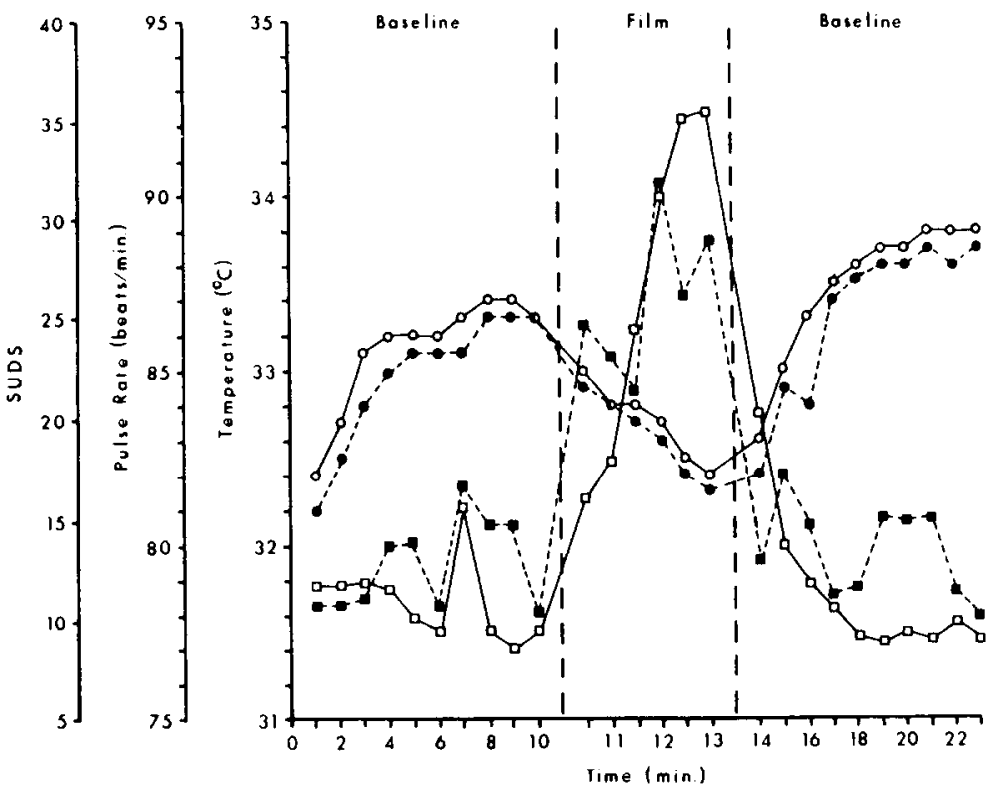

Fig. 1. Autonomic and subjective changes associated with viewing a stressful film. 
Table 1. Spearman Rank-order correlation coefficients between subjective and physiological measures of anxicty: averaged data

\begin{tabular}{lcccc}
\hline & $\begin{array}{c}\text { Subjective } \\
\text { anxicty }\end{array}$ & Pulse & $\begin{array}{c}\text { Left hand } \\
\text { temperature }\end{array}$ & $\begin{array}{c}\text { Right hand } \\
\text { temperature }\end{array}$ \\
$\begin{array}{l}\text { Subjective anxiety } \\
\begin{array}{l}1.00 \\
\text { Pulse }\end{array}\end{array}$ & $0.39^{*}$ & 1.00 & & \\
$\begin{array}{l}\text { Left hand } \\
\text { temperature }\end{array}$ & $0.85^{* *}$ & 0.20 & 1.00 & 1.00 \\
$\begin{array}{l}\text { Right hand } \\
\text { temperature }\end{array}$ & $0.83^{* *}$ & 0.23 & $-0.98^{* *}$ & 1.00 \\
\hline$* P<0.05 * * * 0.01$ & & &
\end{tabular}

in heart rate accompanied increased subjective anxiety whereas peripheral skin temperature decreased. Pulse and skin temperature were not significantly correlated.

Spearman Rank-order correlations were calculated between each individual subject's subjective anxiety scale score, hand temperatures and heart rate. These correlation coefficients are presented in Table 2 and clearly demonstrate that peripheral vasoconstriction is a more sensitive measure of the self-report of anxiety than heart rate. In addition, these results suggest that under certain conditions giving rise to anxiety the subjective anxiety

Table 2. Spearman Rank-order correlation coefficients of subjective anxiety with hand temperatures and pulse: individual data

\begin{tabular}{|c|c|c|c|c|}
\hline Subject & Sex & $\begin{array}{l}\text { Right hand } \\
\text { temperature }\end{array}$ & $\begin{array}{l}\text { I.eft hand } \\
\text { temperature }\end{array}$ & Pulse \\
\hline 1 & F & 0.29 & $0.77^{* *}$ & 0.36 \\
\hline 2 & F & $-0.43^{*}$ & $0.47^{*}$ & 0.07 \\
\hline 3 & $M$ & $0.87^{* *}$ & $0.79 * *$ & 0.39 \\
\hline 4 & $M$ & 0.10 & 0.02 & $0.48^{*}$ \\
\hline 5 & $\mathrm{l}$ & $0.71 * *$ & 0.12 & 0.38 \\
\hline 6 & l: & $0.57 * *$ & $0.60 * *$ & 0.12 \\
\hline 7 & $\mathrm{M}$ & $0.73^{* *}$ & $0.76^{* *}$ & $-^{* * *}$ \\
\hline 8 & $\mathrm{~F}$ & $0.72^{* *}$ & $0.69^{* *}$ & 0.20 \\
\hline 9 & $M$ & $0.72^{* *}$ & $0.73^{* *}$ & 0.20 \\
\hline 10 & $M$ & 0.33 & $0.46^{*}$ & 0.37 \\
\hline 11 & $\mathrm{r}$ & $0.74^{* *}$ & $0.77^{* *}$ & $0.45^{*}$ \\
\hline 12 & $\mathrm{~N}$ & 0.17 & $0.67 * *$ & $0.6 .3 * *$ \\
\hline 1.3 & $\mathrm{M}$ & $0.72^{* * *}$ & $0.69^{* *}$ & $0.43^{*}$ \\
\hline 14 & $\mathrm{M}$ & $0.62^{* *}$ & $-0.51^{*}$ & 0.21 \\
\hline 15 & $M$ & $-0.62^{* *}$ & $0.64^{* *}$ & $0.42^{*}$ \\
\hline 16 & 1 & $0.60^{* * k}$ & $0.64^{* *}$ & 0.01 \\
\hline 17 & $\mathrm{M}$ & $0.54^{* *}$ & $0.55 * \%$ & 0.16 \\
\hline 18 & $\mathrm{~F}$ & 0.30 & 0.36 & 0.10 \\
\hline 19 & 1 & $0.48^{*}$ & 0.29 & $0.68^{* *}$ \\
\hline 20 & 1 & $0.52^{*}$ & 0.13 & 0.23 \\
\hline
\end{tabular}

$* P<0.05 ; * * P<0.01 *^{* * *}$ missing data. scalc predicts certain visceral parameters of the induced affective state in some subjects.

\section{DISCUSSION}

In a critical review of the empirical literature on systematic desensitization, Yates (1975) noted that in many research studies, "Apart from the subject's self-report and casual observation of indices of tension such as sweating and agitated movement, there was little employment of independent indices of tension and relaxation" (p. 174). The results of the present experiment indicate that client ratings of subjective anxiety, quantified in the form of Wolpe's subjective anxiety scale, are moderately associated with two distinct indices of autonomic arousal, heart rate and skin temperature.

It is important to note that the clinical validity of the subjective anxiety scale is not necessarily dependent on having such values highly correlated with theoretically relevant autonomic and behavioral measures. For example, self-report data such as the subjective anxiety scale are frequently the primary outcome measure of interest in clinical behavior therapy and its usefulness is not dependent on concurrent response parameters. Furthermore, highly synchronous changes across response systems appear to be the exception rather than the rule, except at the extreme ranges of arousal. As Lang (1977) has noted, "All response systems are not equally sensitive in their reactions to stress stimuli. They appear to have different scales and one may even be non- 
responding at levels of stimulus intensity to which another system makes a sensitive and palpable reply. Furthermore, it would appear that these scale factors vary considerably among individuals"' (p. 182). The correlations obtained in the present study certainly bear out the latter observation of the above quotation. A similarly wide range of intrasubject variability in response congruence has been found between subjective measures of sexual arousal and penile tumescence (Farkas, Sine and Evans, 1979), suggesting that the critical features giving rise to synchronous (i.e. congruent with autonomic measures) self-reports of affective states and their visceral correlates remain to be isolated.

The present data show that changes in peripheral vasoconstriction are more sensitive to the subjective aspects of anxiety than heart rate. If synchrony between self-report data and psychophysiological responses is held to provide stronger evidence for the existence of change in a subject, clinical researchers may find skin temperature fluctuations a more useful measure than heart rate changes.

This preliminary investigation employed normal college students as the subject sample, and a videotape of minor surgery as the psychological stressor. Replication of this study employing psychiatric patients and their actual anxiety-evoking stimuli is indicated to determine the generalizability of the results.

\section{REFERENCES}

Blakey R. and Baker R. (1980) An exposure approach to alcohol abuse, Behav. Res. Ther. 18, 319-325.

Boudewyns $P$. (1976) A comparison of the effects of stress versus relaxation instruction on the finger temperature response, Behav. Ther. 7, 54-67.

Ciminero A., Nelson R. and Lipinski D. (1977) Selfmonitoring procedures. In Handbook of Behavioral Assessment (Edited by Ciminero A., Calhoun K. and Adams H.), pp. 195 232. Wiley, New York.

Crawford D., Friesen D. and Tomlinson-Keasey C. (1977) Effects of cognitively induced anxiety on hand temperature, Riofeedback Self-Regulat. 2, 139-146.

Curtis G. and Thyer B. (1983) Fainting on exposure to phobic stimuli, Am. J. Psychiat. 140, 771-774.

Farkas G., Sine L. and Evans I. (1979) The effects of distraction, performance demand, stimulus explicitness and personality on objective and subjective measures of male sexual arousal, Behav. Res. Ther. 17, 25-32.

Foa E. and Chambless D. (1978) Habituation of subjective anxiety during flooding in imagery, Behav. Res. Ther. $16,391-400$.
Grey S., Sartory G. and Rachman S. (1979) Synchronous and desynchronous changes during fear reduction, Behav. Res. Ther. 17, 137-148.

Hays W. (1963) Statistics for Psychologists. Holt, Rinehart and Winston, New York.

Hodgson R. and Rachman S. (1974) Desynchrony in measures of fear, Behav. Res. Ther. 12, 319-326.

Hodgson R. and Rankin H. (1976) Modification of excessive drinking by cue exposure, Behav. Res. Ther. 14, 305-307.

Lang P. (1968) Fear reduction and fear behavior: problems in treating a construct. In Research in Psychotherapy (Ed. by Shlien J.), Vol. 3. American Psychological Association, Washington, D.C.

Lang P. (1977) Physiological assessment of anxiety and fear. In Behavioral Assessment (Edited by Cone J. and Hawkins R.), pp. 179-195. Brunner/Mazel, New York.

Leitenberg H., Agras W., Butz R. and Wincze J. (1971) Relationship between heart rate and behavioral change during the treatment of phobias, J. Abnorm. Psychol. 78, 59-68.

Mishel W. (1968) Personality and Assessment. Wiley, New York.

Meyer V., Liddell A. and Lyons M. (1977) Behavioral interviews. In Handbook of Behavioral Assessment (Edited by Ciminero A., Calhoun K. and Adams H.), pp. 117-152. Wiley, New York.

Nunnally J. (1978) Psychometric Theory. McGraw-Hill, New York.

Obrist P. (1976) The cardiovascular-behavioral interaction -as it appears today, Psychophysiology 13, 95-107.

Rachman S. and Hodgson R. (1974) Synchrony and desynchrony in fear and avoidance, Behav. Res. Ther. 12, 311-318.

Spiclberger C., Gorsuch R. and Lushene R. (1970) Manual for the State-Trait Anxiety Inventory. Consulting Psychologists Press, Palo Alto, CA

Tasto D. (1977) Self-report schedules and inventories. In Handbook of Behavioral Assessment (Edited by Ciminero A., Calhoun K. and Adams H.), pp. 153-193. Wiley, New York.

Thyer B. (1981) Prolonged in vivo exposure therapy with a $70 \mathrm{yr}$ old woman, J. Behav. Ther. \& Exp. Psychiat. $12,69-71$

Watson J., Gaind R, and Marks I. (1972) Physiological habituation to continuous phobic stimulation, Behav. Res. Ther. 10, 269-278.

Wincze J., Hoon P. and Hoon E. (1977) Sexual arousal in women: A comparison of cognitive and physiological responses by continuous measurement, Arch. Sexual Behuv. 6, 121-133.

Wolf S. (1979) Anatomical and physiological basis for biofeedback. In Biofeedback: Principles and Practice for Clinicians (Edited by Basmajian J.), pp. 5 30. Williams \& Wilkins, Baltimore, MD.

Wolpe J. (1969) The Practice of Behavior Therapy, 1st Fdn. Pergamon Press, New York.

Wolpe J. (1973) The Practice of Behavior Therapy. Pergamon, New York.

Wolpe J. and Lang P. (1977) Manual for the Fear Survey Schedule. Edits, San Diego, CA.

Yates A. (1975) Theory and Practice in Behavior Therapy. Wiley, New York. 